Letras, Lima. 1977-79 (Nos. 86-87), 61-90.

\title{
Génesis y proyecciones de la guerrilla del 'fiero' Vásquez
}

TOMAS G. ESCAJADILLO

Las peripecias del bandolero Fiero Vásquez dentro del contexto de El mundo es ancho y ajeno necesitan de un esclarecimiento para su correcta comprensión.' Junto con la "historia de Benito Castro "constituyen una suerte de "vidas paralelas" a la comunidad de Rumi, "historias" cuyas relaciones con la historia de la comunidad (peripecia argumental central de la novela) son complejas e importantes, y necesitan, por tanto, de una explicación y análisis demorados. Ya hemos tenido ocasión de examinar el diseño básico que cumplen los cuatro capítulos dedicados a estos dos personajes al estudiar la "Trayectoria y sentido de los comuneros emigrados" en El "mundo es ancho y ajeno" (1). Tanto en ese trabajo. como en el presente, estamos utilizando como punto de partida un estudio general de lá novela: 'Los principios sestructuradores de $E I$ mundo es ancho y ajeno" (2).

Como explicáramos en esos trabajos, los Cáps. 4 (el Flero) y 6 (Benito), constituyen las únicas interpolaciones a la historia de Rumi en el "primer ciclo" de la novela (compuesto por los capítulos 1-8), mientras que los otros capítulos dedicados a estos personajes (Benito: 17 el Fiero: 18) se mezclan con las interpolaciones ocasionadas por las "historias" de los cinco "comuneros emigrados" de Rumi insertas en el "segundo ciclo" de la novela (caps. 9-24).

Hemos visto asimismo la relación de los capítulos de estas dos "vidas paralelas" a la Comunidad con los dos "principios estructuradores" de El mundo es ancho y ajeno; lo que hemos denomi-

(1) "Trayectoria y sentido de los "comuneros emigrados" en El mundo es ancho y ajeno". En: "San Marcos". Lima, UNMSM, No. 18, enero-junio 1977, pp. 92-146. (Hay separata)

(2) "Los principios estructuradores de El Mundo es ancho y Ajeno". En: (Dora Varona, editor) Ciro Alegría: trayectoria y mensaje. Lima, Ediciones Varona, Colección Plenitud, 1972, pp. 206-33. 
nado la Idea Central de la novela ("La comunidad es el único lugar habitable" para el campesino indígena), y el suspenso narrativo, que se produce mediante el "retardamiento del desarrollo de la acción" que provoca la interpolación de diversas historias "independientes", como las dedicadas al Fiero y a Benito Castro.

En un primer examen, la "historia del Fiero" podría considerarse, básicamente, como una suerte de fragmento de una "novela de aventuras"; el capítulo IV destinado a contar "el pasado" del bandolero y el capítulo XVIII dedicado a presentar el misterio en torno a la muerte del Fiero. Estos son los únicos dos capítulos de la novela dedicados exclusivamente al Fiero Vásquez y su aventura humana; son capítulos que, al alejar nuestra atención de la peripecia argumental principal, poseen un claro valor interpolativo que contribuye a crear el suspenso, uno de los dos ejes o "principios estructuradores" que, para mí, tiene la novela.

Para entender correctamente la función y el sentido del Fiero en la novela se hace necesario de un lado un análisis del largo capítulo IV; de otro, es imprescindible rastrear a lo largo de la novela la huella del impacto o influencia de bandolero, desde ese capítulo hasta aquel que cuenta el descubrimiento de "La cabeza del Fiero Vásquez" (XVIII) y el misterio que rodea la muerte del bandolero.

Examinemos, en primer lugar, el complejo capítulo IV. Estamos aquí ante la primera "interpolación" en EMAA, que, al producir el primer "retardamiento del desarrollo de la acción" en la novela, provoca el suspenso en relación al hilo narrativo principal, la suerte de la comunidad de Rumi. El carácter de "novela de aventuras" de la "historia" del Fiero Vásquez se ve- reforzado por una explícita comparación, por parte del narrador omnisciente, con el legendario bandolero Luis Pardo:

Muchas cholitas de los arrabales de los pueblos o de las casas perdidas entre la cresterías de la puna, suspiraban por él. Pertenecía a esa estirpe de bandoleros románticos que tenían en Luis Pardo su paradigma... (3)

Este es el tipo básico que encarna el Fiero al comienzo de la novela, un "bandolero romántico", individualista y "generoso", de la especie de Luis Pardo; aceptemos sin mayor reparo este "tipo básico" para mejor entender las transformaciones del personaje (4) conforme su peripecia vital se va mezclando más y más con

(3) Cito por: Novelas completas. Madrid, Editorial Aguilar (Biblioteca de Autores Modernos), segunda edición, 1963, p. 451.

(4) Es necesario que meditemos en torno a este "modelo" de bandolero que explícitamente escoge Alegría para componer su Fiero. Alegria se suma a quienes asumen la opción "romántica" en relación a Luis Pardo.. Recientemente tenemos por fin una documentación de la vida de Luis Pardo que, si bien se adscribe militantemente a una visión 
el destino de la comunidad de Rumi. Sobre la base de esta presentación, el capítulo IV se desdobla morosa y complicadamente. Primero el narrador hace aparecer al bandolero por el caserío de Rumi, y de inmediato explica esta presencia: es muy amigo del comunero Doroteo Quispe. El narrador omnisciente "realista" cuenta en seguida cómo surgió esa amistad, como resultado de un asalto que tuvo por víctima a Doroteo, pero que terminó con la devolución de lo robado. El capítulo contiene dos historias "enmarcadas": la historia del pasado del mismo Fiero y la historia de un tal Valencio. Esta última historia ha sido relatada, en anteriores visitas, en forma conjunta por el propio Fiero y, complementariamente, por Doroteo y Casiana, la cuñada de Doroteo que se ha convertido en la compañera del bandolero. Doroteo - que tiene un pañuelo que es un salvoconducto para los integrantes de la banda del Fierole pregunta al bandolero por un casi salvaje bandido con quien tuvo un incidente en un paraje desolado; ello da lugar a que el Fiero hable algo de Valencio y complete una primera "imagen" de

idealizadora del famoso bandolero, y no pretende una rigurosa objetividad en el análisis de las fuentes, contiene sí, valiosa documentación que por primera vez se reúne en un solo volumen: Alberto Carrillo Ramírez: Iulus Pardo. "El gran banđido". Lima, segunda edición corregida y aumentada ("Imprenta y encuadernación Yávari 394"), 1976, pp. 264. Este libro recopila la imagen de Luis Pardo tanto en la prosa de ficción peruana (recordando esta alusión a Luis Pardo en EMAA) como en todo otro tipos de textos. (Es lástima, dicho sea de paso, que olvide a José Diez-Canseco, quizás el más entusiasta, de nuestros escritores de primera importancia, de la figura de Luis Pardo, a quien dedica hasta dos textos, el magistral "Jijuna" y el menos conocido "Gaina que come güebo...")

Nos interesa, pues, señalar que tal caracterización inicial del Fiero (aunque en verdad, no esté demasiado respaldada por los hechos de la novela hace más fácil y verosímil la transformación del bandolero en "el brazo armado no oficial" de Rumi. O dicho desde otra perspectiva: en el sugestivo planteamiento del sociólogo Aníbal Quijano, una de las formas "pre políticas" de lucha en el campo peruano, precisamente por los años en que está ambientada El mundo es ancho y ajeno, es la asumida por el "bandolerismo social". Quijano explicita en detalle cuáles serían las diferencias entre un bandolero convencional y un "bandolero social". Pues bien, yo pienso que esta adscripción del Fiero Vásquez al modelo encarnado por el legendario Luis Pardo, implica ya un principio de cierta transformación de un bandolero "convencional" (como los Celedón de Los perros hambrientos, por ejemplo): Luis Pardo (por lo menos en la leyenda idealizadora) sería un "bandolero que roba a los ricos y protege a los pobres", o como dice Carrillo: "Lo complejo de su personalidad no nos permite hallarle su justa ubicación; pero si tenemos en cuenta sus características más saltantes, cuales eran su espiritu filantrópico para con los pobres y su rebeldía ante toda autoridad, podríamos considerarlo como un "anarquista", como un precursor del "anarquismo", antes que un vulgar delincuente" (op. cit., pp. III-IV) Ver las notas 9), 24), 27) y 31 ). 
este importante personaje; luego, en la intimidad de la noche, Casiana le dice al Fiero "Valencio es mi hermano" y el narrador omnisciente "traduce" la historia de la desdichada vida de Valencio, Casiana y Paula, la mujer de Doroteo, como pastores de una gran hacienda. El efecto es similar al producido por el encuentro que, en el tercer capítulo, tiene una comitiva encabezada por Rosendo Maqui con unos pobres pastores de la vecina hacienda Umay. En estas dos oportunidades se ilumina, por el contraste y la antítesis, la Idea Central del libro, "la comunidad, único lugar habitable", uno de los "principios estructuradores" de la novela (5). A su vez el Fiero le cuenta a Casiana el pasado inmediato de Valencio: cómo se incorporó éste a la banda. Repárese en el complicado juego de "enmarcamientos" de los diversos fragmentos de la "historia de Valencio": en un capítulo que muestra al Fiero llegando a la casa del comunero Doroteo en Rumi (en el cual se nos explicita la razón de tal amistad) se recuerda algunas conversaciones sostenidas en relación a Valencio; entre Doroteo y el Fiero se presenta un fragmento del diseño general del personaje, el referido a "Valencio en la actualidad", mientras que, con este trasfondo, en una conversación Fiero-Casiana, se recrea "el pasado remoto", que abarca gran parte de su vida y la de su familia, y se complementa el "pasado inmediato" (cómo fue que llegó a la banda del Fiero) de este personaje "clave" de la novela (6).

Así resulta que la interpolación que causa "la historia de Valencio" enmarcada dentro de la "historia del Fiero" del capítulo IV es de alguna manera menos rotunda al mezclarse la anécdota con hechos relativos a pérsonajes que son miembros de la Comunidad. $E$, igualmente, debe tenerse en cuenta la significación que tiene el relato de las infinitas miserias que pasan 'Valencio y sus padres y hermanos, en tanto destaca, por antítesis, la Idea Central de la novela, "la comunidad, único lugar habitable".

La segunda historia enmarcada es la que se refiere a la vida del propio Fiero. Se regresa al momento inicial del capítulo ("Cualquier día, de tarde, un jinete irrumpió en la Calle Real de Rumi al trote llano de su hermoso caballo negro", p. 449), y, sagazmente, se pretexta la aparición de Rosendo Maqui para que el Fiero Vásquez cuente su vida. Hay varios niveles de este relato que nos interesan; algunos tienen que ver más con técnicas de composición o función que cumple determinado fragmento na-

(5) C.F. "Los principios estructuradores de EMAA", op. cit.

(6) Para el diseño de la composición de este personaje y su función en la novela, véase mi trabajo: "Un monólogo interior en El mundo es ancho y ajeno". En: (varios) La obra de Ciro Alegría. Arequipa, Universidad Nacional de San Agustín, 1976, pp. 109-21. (Una versión ampliada de este texto apareció luego en "Acta Litteraria", revista de la Academia de Ciencias de Hungria) 
rrativo dentro del orbe total de la novela; otros tendrán que ver más con los estratos ideológicos de la misma.

Veamos primero el "modelo" de esta historia. El Fiero comienza por contarle a Rosendo y los demás un momento concreto de su azaroza vida (que llamaremos pretérito " 2 "): cuando recibió una terrible herida y, medio moribundo, llega a la casa de don Teodoro Alegría y doña Elena Lynch. Dentro de esta historia se narra lo que el Fiero le contó a don Teodoro Alegría: el inicio de la "mala vida" del bandolero; cómo fue que de agricultor se convirtió en bandolero. A esto podríamos considerarlo un fragmento que relata un tiempo inicial "l". De aquí regresamos a Rosendo como interlocutor mudo y se nos cuenta la vida del Fiero a las órdenes de Teodoro Alegría, vuelto a la "buena senda". Así, tendríamos fragmentos narrativos que se refieren sucesivamente a tiempos novelados $3,4,5$, etc. Un evento importante de este relato-acontecimiento de la más pura ley de "novela de aventuras" - lo constituye la narración de cómo el Fiero y el hacendado vadearon, de noche, un río con creciente, episodio en el cual casi pierde la vida el ex-bandolero; un extenso relato inmediatamente posterior cuenta la "recaptura" de la hacienda familiar Marcabal, relato "novelesco" si los hay; finalmente el Fiero cuenta cómo dejó de estar al servicio de Teodoro Alegría e intentó, de nuevo, regresar a su casa ("tenía un corralito para trigo y otro para maíz", p. 472) y cultivar la tierra con Gumercinda, su nueva compañera, y su hijo; todas sus buenas intenciones, sin embargo, serán inútiles, y el Fiero será forzado a convertirse nuevamente en bandolero.

Aquí termina la "historia" contada a Rosendo y Doroteo; hagamos ahora un alto para analizar los estratos de tal relato que tienen que ver con "los personajeslElena Lynch y Teodoro Alegría. Ciro Alegría tuvo unos abuelos paternos de tales nombres y, asimismo, las coordenadas de sitios y situaciones corresponden básicamente a su "biografía familiar", especialmente el episodio de la toma de la hacienda Marcabal. El diseño de la caracterización de los personajes está presidido por una actitud evidentemente idealizadora, pues se ha "tomado en préstamo" de las personas históricas de Elena Lynch y Teodoro Alegría solamente rasgos positivos (7); desgraciadamente esta idealización de los abuelos

(7) Compárese la inmaculada presencia de Teodoro Alegría en la novela, con estas declaraciones: "A mi abuelo Teodoro se le puede acusar de muchas cosas. Era déspota, atropellador, desconsiderado, mujeriego, injusto, etc. Como novelista trato de juzgar imparcialmente". En: Mucha suerte con harto palo. Memorias. Ordenamiento, prólogo y notas de Dora Varona. Buenos Aires, Editorial Losada (Cristal del Tiempo), 1976, p. 116. Precisamente lo que no hace Alegría es juzgar imparcialmente. Aquí nos dice que era "injusto"; en la cita del libro que se consigna a continuación, los peones de Teodoro Alegría dicen: "Tiene la mano un poco dura, pero nunca hace injusticias". 
paternos produce una grave distorsión en el libro. En efecto, la Elena Lynch de la ficción narrativa es una suma de virtudes, y Teodoro Alegría se nos presenta como un "hacendado bueno", el único que existe en la novela. Mientras a todo lo largo del extenso volumen no vemos otra cosa que patrones abusivos (recordemos, sobre todo, la terminante sentencia de Benito Castro: "Todas las haciendas eran iguales; en todas daba para sobrevivir, pero no para vivir", p. 522) y haciendas en que la vida es miserable, en concordancia con la Idea Central de la novela ("La comunidad, único lugar habitable"), en este capítulo se introduce, vía el conducto de la "autobiografía familiar", la excepcional aparición de un hacendado "bueno". Es necesario que subrayemos la incoherencia de que Teodoro sea un hacendado "benevolente", que significa un ejemplo, el único en el libro, de un patrón tolerable. Mientras que en todo el dilatado espacio novelado de EMAA se confirma la Idea Central de la novela que apunta a realzar los valores de la Comunidad, en esta instancia se brinda la única excepción a la norma, a través de un contrabando emocional de materiales provenientes de un nivel "autobiográfico" que acceden al mundo novelado. El paternalismo que implica la valoración positiva de Teodoro Alegría es evidente:

... los peones le respondieron "Tiene la mano un poco dura, pero nunca hace injusticias", y todos lo querían porque el po. bre pide en primer lugar justicia aunque sea un poco dura... El Fiero estaba orgulloso de su patrón y se habría hecho matar por él, y así muchos. (p, 476).

A diferencia con lo Jquee sucedeeen Celniesto de la novela, Teodoro Alegría representa la posibilidad de un hacendado aceptable y justo, encarna un tipo de hacendado paternalista que, en el espacio novelado en que aparece, es aceptado por todos y nos remite incluso a la idea de que el tal hacendado "bueno" lo es en parte por razones de "linaje". Obsérvese la evidente "idealización autobiográfica" del siguiente fragmento: "Caray, hombre, caray... $\mathrm{Me}$ has metido en un aprieto. En esta casa, por tradición de la familia de mi mujer y de la mía, se concede hospitalidad a quien llega. Elena, encima de la vieja ley, agrega su bondad". (p. 475)

Debe destacarse, de otro lado, la tajante función interpolativa que tiene esta "historia del Fiero"; se produce el "retardamiento del desarrollo de la acción" y el lector queda en suspenso en relación al juicio de linderos que amenaza la existencia de la comunidad de Rumi. Igual valor interpolativo tiene la secuencia final de la "historia del Fiero", que ocupa un capítulo aparte titulado "La cabeza del Fiero Vásquez" (XVIII). Al ser éstos los únicos capítulos dedicados exclusivamente al Fiero, podría pensarse que la función esencial que desempeña este personaje en la novela es la de pro- 
ducir una "historia", novelesca y sugestiva, que pueda servir para ocasionar interpolaciones en la fábula principal de la novela. Sin que esto deje de ser básicamente cierto, es indispensable analizar la presencia y la función del Fiero Vásquez a lo largo de la novela (o más concretamente, entre el capítulo IV y el XVIII). Para ello será útil recordar que, como se nos explica en el cap. IV, el Fiero es un agricultor, un campesino, y que sólo acontecimientos fuera de su control lo apartan (no una sino dos veces) de la tierra y lo convierten en bandolero.

Una fugaz aparición del Fiero al final del cap. 7 nos hace saber que ahora el bandolero está a disposición de la Comunidad: "Yo estoy aura más allá de El Alto, po esas peñas prietas y amontonadas... Si va pa malo, mándame llamar o vas vos mesma..." (p. 579), le dice a Casiana. Debe recordarse, asimismo, que Rosendo, al terminar el capítulo 4, le propone al Fiero que se convierta en comunero; primero indirectamente (pp. 466-67) y luego de manera frontal: "Si usté deja esa vida, podremos tovía... ¿Qué tendría que usté cultivara la tierra?", p. 488. La respuesta del Fiero es igualmente tajante: "Usté quiere que siembre. A lo que resulte, ni Dios permita, puede que ni ustedes tengan onde sembrar..." (p. 489). Proféticas palabras que revelan el pesimismo del Fiero en torno a la marcha del juicio.

La presencia del Fiero en "El despojo", capítulo final del primer ciclo (1-8) en que se puede dividir la novela ( 8 ), es dominante. Estamos en verdad asistiendo a la fase final de un proceso mediante el cual el Fiero mezcla su destino con el de la comuniaad; por lo tanto, cesa de existir, en tanto historia autónoma - tal como la acabamos de estudiar- la "historía del Fiero" que se interpolaba a la "historia deffuicio de Ia comunidad de Rumi". El Fiero ha transformado a su banda de una pandilla clásica y convencional en una suerte de "brazo armado no oficial" de la comunidad de Rumi. El Fiero, sintomáticamente, en este capítulo que rarra "el (primer) despojo" de la comunidad, está presente en todas partes. En los cuarteles de la hacienda Umay se habla de él y se sospecha que un caporal recientemente incorporado sea en realidad un agente del Fiero; en la comunidad, durante el desarrollo de la asamblea general se habla constantemente de él, dado que una de las opciones que se debaten es la de la resistencia armada al despojo de las tierras comunales (pp. 660-04). Inmediatamente después de la asamblea, un largo fragmento del capítulo pertenece, de alguna manera, a la "historia del.Fiero": es la narración de cómo Casiana (que ha abandonado la asamblea cuando comprende que la cosa "va pa malo") va en busca de la gua-

(8) C.F. "Los principios estructuradores de EMAA" op. cit., p. 212 y ss. También: "Trayectoria y sentido de los "comuneros emigrados" en EMAA", op. cit., esp. pp. 93-106. 
rida de la banda y allí, en compañía de Valencio y de un bandolero manco, espera la llegada del Fiero (pp. 606-20); el sentido del texto es unívoco: "Ahí estaba el Fiero, negro de vestiduras y con un galope de quince leguas metido en el cuerpo, pensando ayudar a los comuneros" (p. 621). Cuando el Fiero llega al lugar de los acontecimientos, el narrador omnisciente cree necesaria una explicación de esta transformación que ha llevado al Fiero, de un bandolero convencional, a una especie de guerrillero que combate a los enemigos de Rumi:

He allí que ahora iba a defender a su modo una causa de justicia. No tenía en la cabeza muchas explicaciones que darse. Recordaba solamente el dolor de su propia vida. ¡Ah, pero ahí estaban ya los mandones! (p. 629).

Y las páginas que siguen muestran, por primera vez en la novela, un segmento narrativo que pertenece exactamente por igual a "la historia del Fiero" que a la "historia de la comunidad de Rumi". El Fiero discute con Rosendo, pero termina por aceptar el veredicto de la asamblea comunal de no resistir por la fuerza; la comitiva da media vuelta y regresa a Yanañahui. Sin embargo, la intuición narrativa de Alegría lo lleva a fabular incidentes finales en este acto de pacífica entrega de las tierras perdidas en el juicio de linderos; con ello consigue, de un lado, crear un clima de tensión que hace que la entrega de tierras no sea tan pacífica; de otro lado, al morir en estos incidentes un comunero (el tejedor Mardoqueo) y un bandolero (el Manco), se grafica una primera imagen de la fusión de la banda del Fiero con la comunidad de Rumi; el destino de la banda esfará desdevahora vinculado estrechamente con el destino de Rumi.

En el capítulo que sigue (el inicial del "segundo ciclo" de la novela) se hacen más profundas -y más complejas - las relaciones entre la banda del Fiero y la comunidad de Rumi. En términos globales podría hablarse de un "triple movimiento" de los fragmentos de la "historia del Fiero", ya desde el capítulo final de la primera parte de la novela (VIII). En lo fundamental, el Fiero y su banda se transforman, de bandoleros convencionales, en el "brazo armado no oficial" de la comunidad; por este movimiento central el Fiero va poniendo progresivamente su banda al servicio de los intereses de la comunidad, hasta el punto que las operaciones de la banda sólo conciernen al ataque a los enemigos de Ru$\mathrm{mi}$ : asalto a la hacienda Umay; castigo a los enemigos de la comunidad. Junto a este "movimiento central" un movimiento "complementario" estaría constituido por la incorporación de un bandolero a la comunidad de Rumi (Cap. XI, "Valencio, en Yanañahui"); el movimiento inverso (e igualmente complementario del "movimiento central") está representado por la salida de algunos comu- 
neros para incorporarse a la banda del Fiero. De éstos, Doroteo Quispe, el viejo amigo (y después concuñado) del Fiero aparece en varios episodios y protagoniza un capítulo íntegro (XIV). Al tomar Doroteo y sus amigos la decisión de entrar en la banda del Fiero con el propósito de vengar a la comunidad, ello mismo refuerza la intención fundamental del Fiero. Se comprenderá, pues, que, al referirse las acciones capitaneadas por el bandolero Doroteo Quispe al castigo contra los enemigos de Rumi, cómplices del "despojo" que se acaba de perpetrar, los fragmentos narrativos relativos "a la banda del Fiero "devienen indistinguibles respecto de aquéllos que cuentan "la historia de la comunidad de Rumi". En el plano de la composición novelística nos encontramos, qué duda cabe, frente a un diseño de las relaciones banda del Fiero/comunidad de Rumi, funcional, armónicamente construido y ciertamente más complejo de lo que siempre ha creído la crítica.

En el capítulo inicial del "segundo ciclo" de la novela se continúa sintiendo la influencia del Fiero; siguiendo su consejo los comuneros deciden apelar y contratar a un nuevo defensor legal, pues el Fiero los ha hecho desconfiar de Bismark Ruiz. El mismo Fiero se apareció un par de veces por la laguna de Yanañahui, a conversar con Doroteo ( $p$. 643). Poco después se informa de la desaparición de Doroteo y dos comuneros más: "Paula se acercó a explicarle./ -Taita, se jueron con el Fiero Vásquez. ¿Tú quś dices? / Y el alcalde Rosendo Maqui, por primera vez en su vida. dejó sin respuesta la pregunta de un comunero" (p. 652); muy pronto se verá las consecuencias de esta incorporación: la primera acción de Doroteo consiste en vengarse de Bismark Ruiz. Y si bien Doroteo y sus dos compañeros - bandoleros novatos, después de todo- son incapaces de mataredl tinterilloo y acompañante (pp. 658-65), y se limitan a robarles las cabalgaduras en medio de la noche, las consecuencias de este acto resultan fulminantes, pues Melba Cortez, cuya naturaleza es sumamente frágil, se sentirá mal, la caminata la congestiona de tal manera que, a poco de llegar al pueblo, muere (pp. 665-70).

Las cosas, mientras tanto, se complican para. la comunidad; Amenábar asalta al postillón que llevaba el correo en el que iba el expediente del juicio apelado a la instancia superior $y$, encima, hace que un hombre vestido de negro vigile la operación, con lo cual la responsabilidad del robo recae presuntamente en el Fiero (p. 649 y p. 672). Antes que termine el capítulo se contará la sangrienta pelea a cuchillo entre Doroteo y un bandolero (pp. 673-78), aue termina en una verdadera batalla campal entre todos los bandidos: "De este modo, los comuneros quedaron realmente incorporados a la banda del Fiero Vásquez" (p. 678). Es interesante anotar que este es el último episodio de la "historia de la banda del Fiero" que conserva la función de interpolación, de "retardamiento del desarrollo de la acción" principal de la novela; estas 
páginas dedicadas al duelo a cuchillo nos distraen eficazmente del juicio de linderos entre Rumi y Amenábar.

Al hacendado de Umary le conviene que se asocie a la banda del Fiero con la comunidad de Rumi, pues así aumenta la responsabilidad penal de ésta; por ello es que, poco después, estando "Rosendo Maqui, en la cárcel" (cap. XI), por haber intentado recuperar ganado de la comunidad que se encontraba en la hacienda Umay, los cargos contra él serón más amplios:

Rosendo estaba acusado no solo de abigeato sino también de instigación al homicidio de don Roque Iñiguez, de tentativa de homicidio de don Alvaro Amenábar y de complicidad y encubrimiento de los delitos del Fiero Vásquez (p. 715)

El carácter "no oficial" de las operaciones de la guerrilla del Fiero contra Amenábar y sus secuaces - así como el cuestionamiento de tales operaciones por personas que, como el bienintencionado pero ingenuo abogado defensor, Correa Zavala, todavía creen en una "salida legal" para Rosendo y para la comunidad de Rumiqueda evidenciado en este diálogo entre Rosendo Maqui y su abogado:

La cosa está que arde en las punas de Umay y por eso don Alvaro no ha podido venir. Dicen que corre mucha bala y que es la gente del Fiero. Una noche, hasta atacaron la hacienda y murieron dos caporales.

Rosendo callaba sin saber qué decir.

- De mi parte, Maqui, Le Gaconsejafía que ejerciera su influencia para que "erminara estaliagitación. Usted es el perjudicado...

- ¿Cree que puedo salir?

-Sí, si se cumple la ley.

-Usté es muy güeno, don Correa, y cree tovía en la ley. Ya verá como nos enredan... (pp. 715-16)

Es importante subrayar que el Fiero determina sus acciones al margen de consultas o contactos con los dirigentes de la Comunidad; así se desprende claramente del "informe" que el nuevo alcalde, Clemente Yacu -nombrado mientras dure la prisión de Rosendo Maqui- hace al ex-alcalde: "Clemente le informó de la asamblea y todo lo que pasó en ella. Nada sabían en detalle del ataque a Umay y la muerte de dos caporales. Corrían las voces de que iba a salir la gendarmería a batir al Fiero Vásquez" (p. 721)

Muy pronto se hace evidente que el hacendado conseguirá que el gobierno mande a la fuerza pública a perseguir al Fiero; pues ya no es un simple bandolero, sino una amenaza a los hacendados, es decir, a la propiedad privada y al orden establecido. 
Estas acciones iniciales de la banda del Fiero parecen tener una relativa eficacia:

Don Alvaro Amenábar y Roldán llegó al pueblo, llevando a toda su familia, de un momento a otro. La noticia entró a la cárcel por boca de un gendarme.

- Llegó el gallazo con la pollada. Alardeaba que al Fiero Vásquez lo iba a hacer lacear con sus caporales y aura corre. Dicen que se ha venido por caminos extraviados y seguro que pedirá que nos manden contra el Fiero... (pp. 722-23).

Es importante de otro lado reparar en la única recomendación que hace Rosendo al nuevo alcalde: "-No den pretexto pa que destruya la comunidad po la juerza..." (p. 722).

Finalmente, se hace efectiva la movilización contra el Fiero; es significativa la reacción en la prisión en torno a la figura del bandolero:

Una noche resonaron cascos de caballos en el patio empedrado . Luego repiquetearon con más violencia, saliendo a la calle y alejándose. Al día siguiente los presos no fueron llevados al sol, con el pretexto de que pronto llovería. Correa Zavala entró a ver a Rosendo y le dijo:

-No los sacan por precaución, pues han quedado pocos gendarmes, a pesar de que la dotación ha sido aumentada. Anoche partieron cuarenta, y se dice que van a perseguir al Fiero Vásquez...

La noticia voló de celda en celda, de cuadra en cuadra. Los presos alentaban unatabierta simpatía por el Fiero Vásquez, a quien juzgaban el vengador de todas las tropelías e injusticias (pp. 739-40; mi subrayado)

Como se ve esta "imagen" que tiene el Fiero en la cárcel -en la que la mayoría de los presos lo están de una manera injustacoincide con la transformación que venimos estudiando que convierte al ex-bandolero tradicional en un guerrillero sui generis que combate a los enemigos de Rumi, a Âmenábar y sus cómplices. (9)

(9) Nos parece pertinente en esta instancia examinar, aunque sea someramente, un aspecto de un ensayo de Aníbal Quijano titulado "Los movimientos campesinos contemporáneos en América Latina", referido específicamente al "bandolerismo social". Quijano considera que hay "dos etapas históricas en los movimientos campesinos, en Latinoamérica". Dentro de la primera etapa, "el período pre-político", figura el "bandolerismo social". Es interesante anotar que Quijano no sólo acepta como fuentes de documentación las habituales en las ciencias sociales, sino que da explícitamente cabida a la prosa de ficción: "Las numerosas formas concretas que adoptaron estos movimientos del campesinado, que se registran en la literatura histórica y narrativa" (p. 31, mi subrayado) se pueden agrupar en cuatro categorias, una de las cuales es la aludida "bandolerismo social". Veamos en esta instancia qué bien calza el 
Y, al mismo tiempo, vía los destinos de Rosendo y el Fiero ("coinculpados"), seguimos presenciando la fusión de la "historia de la banda del Fiero" y la "historia de la comunidad de Rumi" en una sola historia.

Los resultados del operativo contra el Fiero los conocemos dentro del capítulo que cuenta el afincamiento de "Valencio, en Yanañahui" (XII):

Rebotando de cerro en cerro, de picacho en picacho, una tormenta de estampidos llegó una tarde hasta el caserío. Venía evidentemente de muy lejos. Todos los comuneros se asomaron a la puerta de sus casas mirando hacia las cresterías. El viento, por momentos, ayudaba la llegada de los sonidos y la batalla se acercaba. Lloraba la mujer de Jerónimo Cahua; la de Condorumi se puso a trepar el cerro con la esperanza de distinguir algo, y Paula y Casiana callaban con el silencio doloroso que habían aprendido desde su nacimiento. Por primera vez la comunidad se inquietaba ante una distante lucha de bandoleros (...) He aquí que ahora recomenzaban los tiros y tres comuneros daban sus vidas al azar de la contienda. (p. 744; mi subrayado)

Paula y Casiana le sacan a su hermano, trabajosamente, detalles del enfrentamiento del Fiero con los "caporales gendarmes"; (10) los bandoleros han tenido cinco muertos y cuatro heridos, pe-

Fiero Vásquez en la caracterización del "bandclero social": "El bandolerismo social, en cambio, persigue predominantemente finalidades punitivas. A pesar de teneroun claro esentido de protesta social por la irijusticia de los poderosos no llega a tener una "ideología" amplia, salvo la primaria de "rebelión contra el abuso yola opresión exacerbada". (p. 31) C.F. "Los movimientos campesinos contemporáneos en América Latina". En: "Visión del Perú". Lima, No. 2, agosto de 1967, pp. 28-51. Es necesario subrayar la evolución, las transformaciones del personaje del Fiero; nosotros pensamos que este momento de la peripecia del Fiero nos lo muestra totalmente convertido en lo que Quijano llama "bandolero social". En este diálogo con las ciencias sociales podríamos puntualizar lo siguiente: Quijano afirma: "Sobre el bandolerismo campesino la única fuente accesible es la literatura narrativa", y menciona, en primer lugar, El mundo es ancho y ajeno, con expresa alusión del capitulo "El Fiero Vásquez"; como queda analizado en este estudio, ese Fiero inicial evoluciona en la novela hasta ponerse al servicio de la comunidad de Rumi y realizar acciones punitivas contra los enemigos de ésta: este segundo es el Fiero que se adecúa plenamente a la caracterización que hace Quijano de un "bandolero social".

(10) En el "cerebro primitivo" de Valencio se produce una "fusión" de los "caporales" y los "gendarmes"; algo similar pareciera proponer subliminalmente la novela misma. En todo caso conviene destacar que nunca se usa, en toda la extensa novela, sinónimos para "caporales" ni para "gendarmes". Ver "Un monólogo interior en EMAA", op. cit. y "Trayectoria y sentido de los "comuneros emigrados' en EMÁA". p. 113. 
ro aparentemente las bajas en las filas de los gendarmes y caporales habían sido aún mayores; la banda ha sobrevivido a un enfrentamiento frontal. Al margen de los motivos que ha tenido el Fiero para ordenar a Valencio que se integre plenamente a la comunidad (dijo "Que acompañe y trabaje"), nos interesa tan solo subrayar una vez más cómo la red de relaciones entre "la historia de la banda del Fiero" y la "historia de la comunidad de Rumi", se vuelve más compleja y significativa mediante el recurso de hacer que un miembro de su banda (no importa que sea el "primitivo" y "barbaro" Valencio, su cuñado), se convierta en comunero de Rumi. El capítulo es, por lo demás, como lo hemos estudiado en otra ocasión (11), uno de singular importancia en la estructura global de la novela.

Pasa un tiempo, unos cuantos meses, y nos enteraremos de que la banda del Fiero ha sido diezmada y su jefe, finalmente, capturado (12). Después de uno de los capítulos interpolativos que cuentan las peripecias de comuneros emigrados, se nos presenta el dedicado a "El bandolero Doroteo Quispe". Tenemos en él relatos pertenecientes, como se ha dicho, a las dos "historias": venganzas contra los enemígos de Rumi. Pero si la primera operación de este tipo (contra Bismark Ruiz y su amante), nos había mostrado, páginas atrás a unos comuneros-bandidos incapaces de matar, ahora estamos ante "El bandolero Doroteo Quispe", curtido por las peleas -dentro y fuera de la banda-y lleno de odio por la reciente muerte de Jerónimo Cahua. La segunda venganza de Doroteo está dirigida contra Zenobio García y su familia, el mal vecino de Muncha que traicionó alos comuneros en el reciente juicio. Los bandolerosongoroteo, que losecapitaneaba, el forzudo Eloy Condorumi y tres más- se comportan con brutalidad, aunque el gobernador de Muncha, en un golpe de suerte, logra escapar de una muerte segura. Quien no escapará es el Mágico, protagonista del tercer y último episodio de venganza que ejecuta Doroteo. Nuevamente es necesario hacer notar de que la violencia y la brutalidad van en aumento de episodio en episodio, pues en el de Zenobio García resulta que el gobernador de Muncha sólo pierde

(11) C. F."Un monólogo interior en EMAA" op. cit.

(12) La primera noticia del apresamiento del Fiero Vásquez la tenemos dentro de una de las historias de los "comuneros emigrados", la de Calixto Páucar en el asiento minero de Navilca (p. 764), lo cual importa un elemento de "borrosidad temporal", pues la norma temporal de la historia principal es la cronología lineal, mientras que los capítulos de los "comuneros emigrados" están presididos por un afán de vaga simultaneidad en un tiempo no muy identificable. Ver "Trayectoria y sentido de los 'comuneros emigrados' en EMAA", op. cit., p. 119 y "Los principios estructuradores de EMAA", op cit., p. 223. 
"honra (13) y hacienda", mientras que el Mágico hallará feroz muerte en un pantano. El mercachifle había sido perseguido pacientemente ("Días de días llevaban Doroteo y sus segundos por las punas adonde huyeron, acechando inútilmente", p. 781), y cuando se le captura Doroteo desecha la idea de una muerte convencional por bala: lo llevan a un pantano a que se ahogue lentamente; Alegría está en su mejor nivel manejando los incidentes de esta secuencia narrativa. Cuando, en el minuto penúltimo, el Mágico ruega "tengan compasión", la respuesta es tajante: "¿Compasión? ¿Tuviste vos compasión de algo en tu vida?" (p. 787); no hay piedad para los que traicionaron a Rumi, y las razones de la muerte del Mágico son muy claras:

- ¿Cobardes, dices? Tú has sido el gran cobarde. Después de pasar como amigo, te volteaste y también juiste a sonsacar a la gente del Fiero pa ir con el cuento a tu gamonal. Aura sabemos todo: te has fregado... (p. 784)

Luego de la "historia de comuneros emigrados" más extensa, que se interpola a continuación (los padecimientos de Augusto Maqui en una cauchería), la acción nos lleva nuevamente hacia Rosendo ("No sabemos-con precisión cuánto tiempo ha pasado desde la última vez que vimos a Rosendo en la cárcel. Quizá un año, quizá dos. Para el caso, podría hacer seis meses solamente" p. 819). Será la narración del reencuentro, en la córcel, del ex-alcalde y el bandolero, de la fuga de este último y, finalmente, del asesinato de Rosendo Maqui, ejecutado por los gendarmes de la prisión. También será el último episodió en que participa el Fiero, pues a partirJdesaquí desaparecéella huella del bandolero. hasta aquel episodio que presenta el misterio que rodea su muerte (18: "La cabeza del Fiero Vásquez"). Este capítulo, a pesar de estar titulado "Muerte de Rosendo Maqui" (16), es protagonizado, sin embargo, por igual por el Fiero que por el venerable alcalde. Será también la instancia de mayor contacto personal entre estos importantísimos personajes de EI mundo es ancho y ajeno (los más importantes de la novela junto con Benito Castro), Y nos parece, por tanto, necesario examinar con algún detenimiento este episodio de la novela. Como se ha dicho, la fusión de las actividades de la banda y los sucesos de la comunidad implica una vinculación en-

(13) Los bandoleros destrozan la tienda y el alambique de Zenobio García y violan a su esposa y a su hija, la "orgullosa" Rosa Estela (pp. 779-81). Por ello es un tanto inverosímil que Doroteo Quispe, que es quien viola a la hija del gobernador García, como parte de una acción "punitiva" en la que ninguno de los asaltantes actua embozado, se avecine de nuevo en la comunidad de Rumi, colindante con el pueblo de Muncha. 
tre ellas que es alentada desde arriba porque conviene al hacendado y a los poderes públicos:

Un día metieron al Fiero Vásquez a la propia celda de Rosendo. De la 4 pasaba a la 2. Las autoridades los consideraban ya compañeros de proceso, $y$, sobre todo, reuniendo al comunero con el bandido, querían envolver a Rosendo y toda la comunidad en la misma atmósfera delictuosa y culpable (p. 824)

Es interesante notar que pese a que Rosendo es una presencia dominante en este capítulo al cual da título, algunos acontecimientcs que se filtran a la cárcel tienen la virtud de distraer la acción relativa al juicio de linderos, a pesar de que en tales hechos - Ias incidencias de una reciente "campaña electoral" a balazos en la que se enfrentan Amenábar y sus rivales, los Córdova- el hacendado de Umay está presente. Pero, a nivel de acontecimientos, los tiros que se escuchan en la cárcel, y que marcan la existencia de un "clima electoral", nos distraen un tanto. Igualmente, Amenábar, que se había ido a Lima, se eterniza en la capital debido a un asunto de faldas (extranjeras), y el juicio contra Rumi parece haber pasado, por el momento, a un plano secundario. El capítulo contiene el acierto de reunir a Rosendo con Jacinto Prieto (14), el valiente herrero que quiso declarar en favor de la comunidad en el pasado juicio, el único que intentó hacerlo; por eso es precisamente que se encuentra preso Jacinto. Significativamente, el Fiero lo ayuda con dinero y consigue sacarlo de la cárcel

En la cárcel rápidamente el Fiero domina la escena, por su sola presencia y pór sú dinero. Está en constante contacto con su banda - de la cual recibe dinero y a la cual le da directivas$\mathrm{y}$ por orden suya los bandoleros se han puesto en contacto con los Córdova para "ayudarlos" en la "campaña electoral" contra un hijo del hacendado de Umay, que se ha lanzado de candidato a una diputación. El Fiero recibe también constantemente la visita de Casiana y su hijo "que ya comenzaba a caminar". Un solo acontecimiento de este capítulo carcelario nos remitiría a una

(14) Jacinto Prieto, junto con Correa Zavala y hasta el "loco pierolista" (personaje del pueblo que acostumbra entrar y salir de la cárcel principalmente por sus burlas a los poderosos) cumplen la función de significar que, pese a todo $y$ aunque sea en forma limitada, existe la "solidaridad humana" sobre la tierra. He fundamentado, de otro lado, que este personaje representa el diseño básico del que luego se llamaria "Calixto Garmendia", personaje protagonista de un cuento por largos años antes de que se descubriera que era en realidad un personaje y una anécdota sacados de la novela Lázaro. Cf. mi tesis doctoral: La narrativa indigenista. Un planteamiento $\mathbf{y}$ ocho incisiones. Lima, UNMSM, 1971, p. 45. 
"historia del Fiero" autónoma de la historia de Rumi: la reaparición de su ex-compañera, Gumercinda, de la cual no había vuelto a saber nada.

Es interesante notar que entre el Fiero y Rosendo se establece una corriente de simpatía y solidaridad pero la comunicación entre ellos es más bien parca: "se llevaban bien, pero no sería exacto decir que intimaban" (p. 825) Las diferencias entre ellos son las mismas que los dividieron en cuanto a resistir o no el despojo de las tierras comunales; en el horizonte espiritual de Rosendo está siempre presente la tierra y esto lo hace pensar sedentariamente, mientras que el horizonte del Fiero es ilimitado: el bandolero es básicamente nómada. Estas diferencias se agudizan cuando el Fiero trata de convencer a Rosendo de que lo acompañe en su bien planeada pero riesgosa fuga; veamos sus reacciones iniciales:

Rosendo se puso a mascar su coca. El Fiero prendió un cigarrillo y revisó las ganzúas y la carga del revólver. El viejo consideraba lo que podía sucederle en caso de que lograran escapar. El bandido solo se preocupaba del éxito de la fuga misma. Más allá del muro, quedaba su mundo de riscos, cavernas y balazos. (pp. 831-32).

Es decir, mientras Rosendo piensa como campesino, y por lo tanto como una persona atada a la tierra, el Fiero encarna al fuera-de-laley sin atadura alguna, en la tradición del auténtico outlaw de tantas corrientes novelescas. Volveremos después a este punto.

El Fiero, pues ha preparado cuidadosamente su fuga; sabe perfectamente que su situación se há complicado grandemente al estar asociado con lar resistencia armada de la comunidad de Ru$\mathrm{mi}$, no sólo porque ahora tiene un muy poderoso enemigo, Amenábar, sino porque se ha salido de los módulos habituales con que operan los bandoleros: ahora es, además de todo lo anterior, una amenaza a la propiedad privada y el orden establecido. El narrador omnisciente nos hace saber que también el Juez del proceso piensa igual:

El juez, sabiéndolo en sus manos, no se daba el trabajo de acosarlo mucho. Por momentos, hasta tomaba una actitud que quería decir: "Yo no te reclamo, sino Amenábar. ¿Para qué te metiste con los comuneros?" (p. 824)

El capítulo continúa con la "novelesca" fuga del Fiero y el asesinato, que se realiza inmediatamente después de la escapatoria, de Rosendo Maqui: los gendarmes lo ultiman a culatazos de fusil (15). Todavía sobrevive unas cuantas horas el venerable

(15) En un texto publicado en la revista "Texto Crítico", en el 
alcalde, y dos espléndidas páginas, que no es la ocasión de glosar (16), nos introducen al fluir de la conciencia de Rosendo ("No suplo claramente cuando volvió en sí. Su conciencia era una flotante niebla", p. 837) en sus últimos momentos de vida. Todo ha concluido; Rosendo ha muerto y el Fiero ha logrado escapar.

Aquí termina la vigencia del Fiero en la novela. Alegría, sin embargo, fabula un episodio final (17) que se refiere al misterio de la muerte del bandolero, capítulo que, como hemos afirmado,

cual discuto la problemática de la obra de Alegría a raíz de la aparición de sus Memorias, examino una anécdota del "sistema literario" en relación a $\mathbb{E l}$ mundo es ancho y ajeno; cómo, en la versión de dibujos ánimados de la novela, que "Expreso" publicó entre 1962 y 1965 (Gonzalo Mayo dibujante) la muerte de Rosendo Maqui (en la versión que el propio Alegría proporcionaba a "Expreso" se acentuaba la denuncia al hacer que el propio subprefecto golpee al alcalde con un bastón) tiene, en el texto definitivo este enunciado: "Rosendo sintió como un puñal de fuego en el corazón. Era el traicionero infarto". La verdadera traición es la de quienes manipulan los mensajes emitidos por el "imparcial" "Expreso" de aquellos días. Misterios de la "decodificación" amparada por la S.I.P. En un ejemplo de sarcasmo seguramente involuntario "Expreso" incluye esta información, que era una novedad, pues nadie sabía hasta qué punto había sido violada la voluntad de Aleøría, en el "Homenaje" que se le tributó al novelista con motivo cie su muerte. C.F. "Estampa" (Suplemento dominical de "Expreso"), Lima, 26 de febrero de 1967, p. 4. Ver (T.G.E.): "Alegría habla a los diez años de su muerte. Reflexiones, observaciones y reparos a partir de la aparición de sus Memorias". En: "Texto Crítico". Xalapa, Revista del centro de Investigaciones Lingüístico-Literarias de la Universidad Veracruzana, Año IV, número 11, Septiembre a diciembre de 1978, pp. 132-34.

(16) Véase un estudio muy detallado del fluir de la conciencia de Valencio en: "Un monólogo interior en EMAA", op. cit. Este fluir de la conciencia que interpreta los últimos instantes de la vida de Rosendo representa un segundo monólogo interior, menos importante, en la novela. Repárese como, junto a otras ideas e imágenes "esperables", una de las últimas ideas que visita la conciencia de Rosendo es aquella de los tiempos antiguos "en que todo era comunidad"; veamos el logrado final del monólogo interior del agonizante alcalde: "El maizal luce barba de hombre y el trigo echa espigas de sol. La campana de la capilla canta. Pascuala teje una bella frazada de colores... El buey Mosco ha ido por sal y ya lenguetea el bloque de sal de piedra... El viejo Chauqui cuenta que todo era comunidad y que los comuneros de Rumi decían ser descendientes de los cóndores. Esa es la flauta de Demetrio Sumallacta, como el canto de las torcaces. Revolotean las torcaces sobre la quebrada lila de moras. De la quebrada baja la acequia de agua que brilla al sol en cierta curva. En el arpa de Anselmo canta una bandada de pájaros amanecidos... 'iNo me peguen!' ‘No me peguen!' ¿Por qué lo golpean así? ‘No me peguen!' " (p. 838)

(17) Digo "fabula" por lo funcional de este episodio final, con su impenetrable misterio, en la estructura total de la novela; a pesar de que Alegría explicaba que las circunstancias de la muerte del Fiero "en la novela" corresponden exactamente a aquellas de la muerte de este personaje "en la realidad". C.F. nota 19. 
devuelve el valor interpolativo que tuvo inicialmente (cap. V) la "historia del Fiero". Es más, este capítulo está inserto en un "bloque" de cuatro capítulos (XVII-XX) que posee una clara función interpolativa: durante numerosas páginas nos hemos alejado de la historia del (segundo) juicio de linderos que amenaza la existencia misma de Rumi (18).

Este misterio, que Alegría ha justificado un tanto simplísticamente aduciendo razones de "realismo" (19), implica casi la única instancia en la totalidad de la novela $(20)$ en que el narrador omnisciente viola su norma de "explicarlo todo", parte importante de la "poética" narrativa de la novela. Esta ruptura de la norma es a todas luces un acierto, porque el profundo misterio que rodea la muerte del Fiero le devuelve a su historia el carácter que tuvo, en un primer momento (cap. V), de "novela de aventuras". En efecto, ninguna de las hipótesis - de diversos personajes secundarios y del narrador mismo- puede explicar por qué se encontró -oculta, pero no mucho-, en un paraje semi-desolado, la cabeza del famoso bandolero, ni por qué fue separada la cabeza del cuerpo, que nunca fue hallado. La banda del Fiero, en su última aparición en la novela, está igualmente desconcertada:

La noticia llegó al seno de la banda y todos blasfemaron amarga y rabiosamente. Doroteo lloraba mascullando: "Y aura me doy cuenta de que lo quería al maldito..." Tenían que saber quién lo mató y entonces... Pero no existían siquiera indicios. El Fiero se marchó solo diciendo que regresa-

(18) C.F. "Los principios estructuradores de EMAA" op. cit., pp. 215-16, y "Trayectoria y sentido de la peripecia de los "comuneros emigrados" en EMAA", op. cit., p. 137.

(19) Véase una famosa declaración: "Una norteamericana me pedia explicar la muerte del Fiero Vásquez, cosa que no he querido hacer convencionalmente y si respetar en su misterio, porque como lo cuento ocurrió". En: "Prólogo a la décima edición" (De EMAA). Cito por: Novelas completas, op. cit., p. 331.

(20) Los únicos otros "misterios" no explicados por el narrador cmnisciente son el relativo a una mujer, cuyo cadáver sin la menor señal de violencia fue encontrado por Benito Castro, y nadie de la comunidad pudo averiguar nada de ella (pp. 375-76). Él segundo misterio es ilustrativo del prurito explicativo que impera en la novela ("Explicaremos lo necesario a su tiempo", p. 369): siendo Benito Castro suldado, poco antes de su retorno a Rumi, una mujer sorpresivamente lo llama por su nombre, momentos antes de su fusilamiento. ¿Quién era? ¿Gente de Rumi? El narrador omnisciente explicita que en esta instancia no se guiará por el principio "realista" de explicarlo todo: "Recordemos nosotros que cuando comenzó el éxodo de comuneros hacia el mundo, callamos muchos nombres. Ahora no creemos necesario aclarar si esa - esos fusilados pertenecían o no a la comunidad. Su grito nos parece, más bien, el reclamo clamoreante del pueblo: '¡Defiéndenos, Benito Castro" " (p. 902). 
ría dentro de una semana, pero sin especificar adónde iba. (p. 961)

Esto es lo último que se sabe de la banda.

Al revisar la "historia del Fiero Vásquez" en su integridad, hay ciertos puntos que merecen un análisis final. El primero es la relación del bandolero con la tierra, relación cuyo sentido hemos comprendido un poco más al examinar la discrepancia Fiero-Rosendo a raíz de la proyectada fuga del bandolero. De otro lado, creemos que tiene significación el que se haya explicitado que, en el fondo, el Fiero no es otra cosa que un pequeño (o pequeñísimo) agricultor llevado por las circunstancias al delito y a la vida fuera-de-la-ley. Se pudo regenerar una vez (en el episcdio de Teodoro Alegría, que es, como vimos, ideológicamente confuso y has. ha contradictorio respecto del resto de la novela en su totalidad); muchos años después, Rosendo Maqui lo invitaría a formar parte de la comunidad de Rumi ("¿ué tendría que usté cultivara la tierra?"), pero el Fiero considera que ya está demasiado incriminado y que dañaría a la comunidad, la que, por otro lado, está a punto de perder sus tierras: "A lo que resulte, ni Dios permita, puede que ni ustedes tengan onde sembrar..." (p. 489). El tema se repetirá a lo largo de la novela; el narrador, por ejemplo, se preocupa de subrayar el día y el instante preciso en que Casiana finalmente "comprendió que esa era su vida y que la tierra no lo re conquistaría más". "(p.g744) sciYeen Celnmomento en que Rosendo toma la determinación de no acompañar al Fiero en su fuga, el motivo de las relaciones campesino/bandolero se hace más complejo y variado:

Te agradezco, amigo. Vos no crees del todo que ganará Amenábar y yo sí. ¿Qué sería de mí en este caso? Vos tienes la puna, las cuevas, los caminos, la salú y la juerza pa irte po un lao y otro. Yo soy un viejo inútil pa la lucha con el cuerpo. Al triunfar Amenábar, me perseguirán y agarrarán, y si no, peor. Con el pretexto de buscarme, cometerán mil abusos con la comunidá. No arreglo nada fugándome. Si salgo de aquí, que no creo, saldré para ver la tierra cultivada, pa alegrarme con su contacto... La fuga y el escondite son pa mí como la cárcel y peores... iY tanto comunero que puede morir y padecer po mí sin que sea necesariol (p. 833; mi subrayado).

Está claro que ya para entonces la tierra no reconquistará nuevamente al 'Fiero'. Por lo tanto se produce la discrepancia básica 
entre Rosendo y el Fiero. Uno tiene la visión del mundo sedentaria que corresponde a un campesino; el o!ro ve el mundo con una actitud de un nómade, lo que corresponde a su condición de bandolero o guerrillero. Y junto con ello, Rosendo piensa siempre en las consecuencias que puede causar su fuga en la comunidad. No olvidemos cuál es el último consejo-orden que le da Rosendo al nuevo alcalde de Rumi: "No den pretexto pa que destruyan la comunidá po la juerza". Todo ello nos explica asimismo la divergencia que tuvieron Rosendo y el Fiero en cuanto a si se debía o no resistir por las armas el primer despojo. Pero tengamos cuidado de exagerar estas diferencias y discrepancias. En lo relativo a pelear o entregar pacíficamente las tierras, Rosendo y el Fiero encarnan, en verdad, al sector mayoritario y al sector minoritario, respectivamente, de la comunidad; son, pues, la muestra de dos tendencias contrarias que existen al interior de Rumi, antes que actitudes que puedan llevar a sustentar la tesis de una absoluta ruptura entre Rosendo y el Fiero Vásquez. La verdadera ruptura se produjo cuando el Fiero es ob!igado, por segunda vez, a dejar de cultivar la tierra, y a convertirse nuevamente en bandolero. Si de un lado - como seguiremos viendo en las páginas que siguen- hay más cercanía entre bandolero/campesinos de lo que acarece en una primera lectura de la novela, de otro bien puede considerarse que el sentido que falta a la vida del Fiero desde que, contra su voluntad, fue alejado de la tierra, lo reencuentra el ban. dolero al adoptar, de motu propio, la causa de los comuneros de Rumi, es decir, de quienes sí cultivan la tierra. Finalmente, en la cárcel el Fiero juega con su pequeño hijo -que reaparecerá, años después, en las últimas páginas de la novela-, a quien Casiana, que llega acompañada de otrós comuneros que visitan a Rosendo. siempre lleva; este hijo, luego bautizado como el Fierito, ya es un comunero libre de Rumi, que colmará sus aspiraciones vitales y dará sentido a su vida cultivando, él sí, la tierra.

A lo largo del presente trabajo hemos visto $y$ analizado con cierto detenimiento cómo el Fiero no es un bandido convencional, al promediar la novela, sino que es un guerrillero, y su banda es una suerte de "brazo armado no oficial" de la comunidad de Rumi. La crítica imperante sobre El mundo es ancho $y$ ajeno ha visto al Fiero como un bandolero tradicional, de molde "clásico", y por tanto ha "separado" siempre las dos historias (como efectivamente lo estuvieron, como se ha visto, en la primera parte de la novela). haciendo que la "historia del Fiero" tenga solamente una función interpoladora que produce un "retardamiento del desarrollo de la acción" principal, como sucede con la "historia de los ban. 
doleros Celedón" en Los perros hambrientos (21). No dejan de existir a este respecto desaciertos críticos mayores: Luis Alberto Sánchez, por ejemplo, afirma:

... los últimos recuerdos se agolparon en la mente del escritor, y éste no tuvo fuerzas para disciplinarlos; se dejó arrastrar por el turbión, e hizo de dos novelas, una, porque la novela de Rosendo Maqui es distinta de la del "fiero Vásquez": la una pertenece al agro-tradicional, la otra al agro-en-trance de fugaise a la ciudad. Aquella es solemne y dolorosa; ésta, traviesa y audaz. (22)

Nos parece innecesario refutar estas afirmaciones porque casi todo el presente estudio implica la contradicción de tal planteamiento, que separa tajantemente (hasta el punto de hacerla constituir "otra novela") la "historia del Fiero" de la "historia de Rumi".

Volviendo a la verdadera condición del Fiero, es indudable que la postura crítica que ve en él un bandido tradicional, cuya única función novelística sería (al igual que lo que ocurre con los bandoleros Celedón en Los perros hambrientos) la de brindar fragmentos de "otra historia", que pueda interpolarse a la fábula central, es una postura incorrecta, equivocada. Las relaciones entre el Fiero y la comunidad de Rumi (especialmente entre los caps. 4-18) son complejas, importantes, variadas y profundas, como hemos visto a lo largo de las presentes páginas. En lo que ahora nos concierne, el razonamiento que considera significativa la transformación de la banda del Fiero de una banda "tradicional" en el "brazo armado no oficial" de Rumi, nos' parece de capital importancia. De un lado, estaltransformación hace que "cobre sentido" la existencia del Fiero (que no es un "bandolero por vocación" sino un agricultor frustrado: trabajar la tierra es lo que en otra época le daba sentido a su vida). De otro lado, la fusión de la banda con la comunidad de Rumi tiene claras consecuencias ideológicas: contribuye a que se forme una imagen más beligerante de la comunidad e implica una mayor aceptación - hacia el interior del mundo novelado- de la violencia con fines revolucionarios.

Esta fusión, ya estudiada, se completa cuando "los restos" de la banda del Fiero (Doroteo Quispe, Eloy Condorumi y "unos cuan-

(21) C.F. el análisis que hace Antonio Cornejo Polar de las funciones interpolativas de los bandoleros Celedón. En: "La estructura del acontecimiento de Los perros hambrientos", en: "Letras". Lima, UNMSM, Nos. 78-79, 1967, pp. 5-25 (Hay separata); reproducido en: Ciro Alegría. Trayectoria y Mensaje, op. cit., pp. 155-85, y luego en: La novela peruana. Siete estudios. Lima, Editorial Horizonte, 1977, pp. 65-84. Ver también (T.G.E.): "Los principios estructuradores de EMAA", op. cit., pp. 211-12.

(22) La literatura peruana. Segunda edición. Lima, Ediciones de Ediventas, 1966, Tomo IV, p. 1493. 
tos más" pp. 908-9) se incorporan a la comunidad de Rumi (23). Poco después se les verá peleando de la misma manera que antes. es decir, con las armas, pero ahora ya no como bandoleros sino como comuneros de Rumi.

¿Qué busca Alegría al hacer que estos hombres armados se unan a los campesinos? ¿Nos está proponiendo -como examinaremos después- un determinado "modelo" de resistencia campesina? $\mathrm{El}$ esclarecimiento profundo de las diferencias entre la trayectoria y sentido de la banda del Fiero y aquellos de la banda de los hermanos Celedón (24) nos lleva ciertamente a interrogantes extremas.

Hagamos un alto, asimismo, para subrayar y resumir el hecho que el Fiero influya significativamente en los destinos de Rumi. Después de Rosendo Maqui y de Benito Castro, el Fiero Vásquez es el personaje que más influye en los destinos de Rumi. El carácter "no oficial" de las operaciones de su banda, que hemos examinado, no impide que el Fiero Vásquez sea un "actante" de capital importancia para Rumi, ya desde el capítulo final del "primer ciclo" de la novela, "El despojo". El "triple movimiento" de la banda del Fiero que hemos analizado ilustra lo complejo y sutil de las relaciones entre los bandoleros y la comunidad de Rumi y confirma la enorme vigencia de aquélíos en esta última. La comunidad, por ejemplo, queda vengada de casi todos sus enemigos por acción de bandoleros-comuneros; casi todas las traiciones y abusos come-

(23) El texto nos presenta a unos bandoleros que no abandonan su peligrosidad ni sus armas al reincorporarse a la comunidad: "El postillón, a solicitud de Correa Zavala, fue acompañado por veinte gendarmes que debió proporcionar la subprefectura y otros tantos comuneros que acudieron voluntariamente. Entre ellos, disimulando sus carabinas bajo los ponchos, iban Doroteo Quispe, Eloy Condorumi y unos cuantos más de la banda del Fiero Vásquez, quienes, al morir su jefe, se avecindaron a la comunidad". (pp. 908-09).

(24) Los Celedón responden totalmente a un tipo de bandolero "tradicional". (Hemos visto que el Fiero Vásquez se diferenciaba en algo, desde un primer momento, del bandido "convencional", pues, como su paradigma, Luis Pardo, participa (por lo menos en la sentencia del narrador omnisciente si no en el mundo novelado) de ciertas notas que lo distinguen como "generoso", que "roba a los ricos" y "ayuda a los pobres"). Recordemos que los Celedón de Los perros hambrientos tienen virtudes humanas y son tratados positivamente por Alegría. Pero las "operaciones" de los Celedón carecen por completo de sentido social. Veamos las diferencias entre ambos tipos de bandoleros, en el esquema de Quijano "(el bandolerismo social) se diferencia de las formas comunes de bandolerismo, porque su acción va dirigida predominantemente contra los poderosos, se apoya en la adhesión de la masa campesina, $\mathrm{y}$ las acciones punitivas tienen el sentido de la defensa de los campesinos". Op. cit., pp. 32-33. El cotejo contextual de la violencia en ambas novelas produce precisamente el resultado de una evolución como la que Quijano sugiere para el "bandolerismo social" con respecto a su antecesor, el "bandolero tradicional". 
tidos contra la comunidad reciben su castigo (25). Y, desde la prisión o fuera de ella el Fiero provoca muchas decisiones de la comunidad de Rumi: la de repudiar a Birmarck Ruiz y contratar al abogado Correa Zavala, por ejemplo. Asimismo la contrapartida al castigo a los traidores y desleales a la comunidad de Rumi está en la importante ayuda económica del Fiero a Jacinto Prieto, el único y leal amigo de Rumi, que está preso por haber intentado declarar en favor de la comunidad con arreglo a la verdad; esos mil soles del Fiero podrán hacer lo que no pudieron las cartas de Jácinto Prieto al Presidente de la República o a los periódicos: sacarlo de la cárcel. Se puede afirmar, por tanto, que hacia la mitad de la novela ya se ha unimismado el destino del Fiero con el destino de la comunidad; la suerte de Rumi decidirá la suerte de la banda del Fiero; simbólicamente la destrucción final de la comunidad de Rumi significa también la desaparición de los residuos de la banda del Fiero. O dicho de otra manera: la comunidad de Rumi tendrá el mismo fin que la banda del Fiero: el aniquilamiento y la dispersión. Lejos de constituir el relato de un personaje anecdótico y "novelesco" cuya historia sólo tendría una función de interpolación con relación a la historia principal de la comunidad de Rumi, la "historia del Fiero" - a partir de determinado momento- se imbrica $\mathrm{y}$ fusiona con la historia de Rumi: una de las consecuencias de ello, como hemos visto, es que el jefe de la banda, convertido ahora en un guerrillero sui generis, influya con sus decisiones en la vida de la comunidad. Un valor simbólico complementario a todo ello está en el hecho de que el hijo del Fiero -que ahonda enormemente la relaciones familiares que el Fiero ya tiene con comuneros de Rumi- será en el futuro un comunero libre de Rumi y -quizás- aun unó des sus dirigentes.

Me gustaría ahora, para llegar a la parte final de este trabajo, examinar las diferencias y relaciones entre el Fiero Vásquez y Benito Castro, de un lado; personajes que en diversa manera encarnan

(25) Notoriamente, Amenábar no es castigado en absoluto. De variadas formas, los enemigos de Rumi son objeto de acciones punitivas; el tinterillo enemigo apodado "el araña" y el falso testigo (e igualmente falso "amigo" de Rumi) conocido como "el mágico", mueren violentamentc. Zenobio García "pierde honra y hacienda"; en cuanto al traidor Bismarck Ruiz la muerte de Melba Cortez lo castiga duramente; encima de ello, al final de la novela lo vemos en "franca decadencia" profesional (p. 910). Esta notoria omisión está relacionada con uno de los "condicionamientos" de la novela indigenista: el principio de que no es consistente que los campesinos indígenas pierdan sus luchas "en la realidad" pero las ganen "en el papel" (en la novela). Asimismo, la narrativa indigenista no participa de la vocación de indagar en el espacio más interno del alma humana de otras modalidades narrativas, para las cuales "el crimen" esta indisolublemente ligado, desde un punto de vista conceptual y desde el desarrollo narrativo también, al "castigo". 
la violencia y la resistencia armada, y Rosendo Maqui, de otro, en tanto el venerable alcalde implicaría una supuesta "pasividad" tradicional. Alguna crítica exagera la diferencia entre los líderes "tradicionales", como el ciertamente prudente Rosendo Maqui, y los dirigentes "modernos", abiertos al "progreso", como Benito Castro (26). Existe esta diferencia pero ella no es abismal. A Rosendo le parece que -en el momento y las circunstancias en que le toca regir los destinos de Rumi, en la primera.parte de la novela- lo más aconsejable es el cauteloso camino que implica la pacífica entrega de las ancestrales tierras comunales. Benito Castro piensa que -en las circunstancias extremas específicas en que le toca actuar, como dirigente máximo de la comunidad, hacia el final de la novela, circunstancias que son muy distintas a la coyuntura en que se encontraba la comunidad bajo el mando de Rosendono le queda a Rumi otra salida que la resistencia armada.

No hay, pues, un pasado "tradicional" en Rumi que represente básicamente la "pasividad"; recordemos que en la asamblea comunal que debía decidir los destinos de la Comunidad - asamblea celebrada al margen de la intervención del Fiero Vázquez y mucho antes del regreso de Benito Castro- la resistencia armada contó desde el primer momento con varios partidarios. Ia presencia de Benito Castro de regreso a la Comunidad - puesta en este contexto- significa una activación y más eficiente organización de los gérmenes de la rebeldía que existen en el seno de la Comunidad (27). Es indudable, asimismo, que este personaje significa

(26) Un reflejo delello se encuentra en las siguientes palabras de Alegria: "Un londinense descubría en Rosendo Maqui las mejores cualidades del dirigente popular. Los más radicales de los lectores votan en favor de Benito Castro". En: "Prólogo a la décima edición" (de EMAA). Cito por: Novelas completas. op. cit., p. 331 .

(27) Es interesante notar cómo ios acontecimiento relatados en 1 mundo es ancho y ajeno, y su precisa datación, coinciden plenamente con las actuales investigaciones de las ciencias sociales sobre problemas y levantamientos campesinos. El tiempo de la novela avan\%a cronológicamente (a excepción del capitulo en que se narra la expulsión de Benito Castro, que retrocede hasta 1910) desde 1912 hasta 1928 . Se puede decir que los años más recientes de la novela ilustran bastante bien la problemátiva general del oncenio de Leguia (a quien se alude en el texto), 1911-1930, tal como ha sido estudiada muy especialmente por Wilfredo Kapsoli (C.F. nota 29). De otro lado, la resistencia armada (1928) final, con las alusiones a un levantamiento general en una vasta región ("si llega a prender una buena revolución..." dice Benito), son un anuncio de los nuevos tiempos de una rebelión más consciente que, según Anibal Quijano, se da a partir de los años 30: "Las formas pre-políticas de la movilización campesina parecen haber sido las predominantes en América Latina, hasta aproximadamente, los años 30 de este siglo, época en que se inicia el desarrollo de un nuevo tipo de conciencia social entre los campesinos y, en consecuencia, nuevas formas de movilización". (Op. cit., p. 32). 
una "flecha arrojada al futuro" cuyo cabal sentido es indispensable buscar.

Hemos argumentado, en relación a Rosendo Maqui y el Fiero Vásquez, que no debe exagerarse las diferencias que existen entre estos dos personajes, ni sacarse tales diferencias fuera de contexto. Recordemos, por el contrario que, por ejemplo, ambos comparten un mismo desprecio por "la ley"; ambos tienen la misma actitud escépíica en relación a la ley cuando dialogan con Correa Zavala, su común abogado. Ni el Fiero ni Rosendo creen en la "lucha legal" - a diferencia del un tanto ingenuo Zavala, miembro de una Asociación Pro Indígena-, pero mientras el Fiero adopta la actilud de combatir las leyes (y el "orden establecido") mediante la violencia de las armas, Rosendo huye de ellas, pues "la ley es una peste" (28): las leyes, en su reiterada opinión, sólo sirven para oprimir al indio. Hemos visto que cuando Correa Zavala le recomienda a Rosendo que "ejerciera su influencia para terminar con la agitación" del Fiero (acaba de saberse del asalto a Umay), pues ello perjudica el proceso del ex-alcalde, Rosendo Maqui permanece indiferente: no parece prestar ninguna atención al consejo de su abogado: no cree en la ley ni en la justicia de los tribunales de la República.

Quizás lo que sí pueda decirse es que ciertos rasgos de la personalidad de Benito Castro y, sobre todo, su vasta experiencia humana en el "ancho y ajeno" mundo, lo convierten en el símbolo de una nueva y más honda toma de conciencia, por parte del campesino, del mundo que lo rodea. La memorable frase de Rosendo sigue siendo básicamente válida: "No den pretexto pa que destruyan la comunidá po la juerza"; pero las circunstancias han variado. El segundo despojo, Pqueiles quita a los comunreos las tierras "malas" de Rumi (las "peñolerías de Yanañahui"), y al dejarlos sin tierra alguna, convierte a los comuneros libres de Rumi en virtuales peones de Amenábar (o mineros del vecino yacimiento que aspira explotar), difiere ciertamente del primero (29). Es sin-

(28) Es sintomático que con todo el odio y el temor que siente por "la ley", Rosendo se limita a decir: "iComuneros, témanle (a la ley) más que a la peste!" (p. 350). La actitud de Rosendo es la de evitar y huir de la ley. Benito Castro (que representa un nuevo tipo de dirigente que implícitamente propugna "coexistir" con el "mundo de afuera". lo que incluye por cierto "Ias leyes de la república") comparte el odio por las leyes que siente Rosendo, pero canaliza tal odio, al no quedar prácticamente alternativa, en la rebelión armada. C.F. "Trayectoria y sentido de la peripecia de los "comuneros emigrados" en EMAA", op. cit., pp. 116-17.

(29) C.F. nota 27) El detallado análisis que hace Wilfredo Kapsoli (en algunos casos junto con Wilson Reátegui) de la problemática del campesino andino durante el oncenio (1911-30) de Leguía se relaciona con muchos de los materiales de El mundo es ancho y ajeno; la novela es, pues, ilustrativa de las tensiones históricas de su referente de rea- 
tomático e ilustrativo, de otro lado, que el último alcalde de Rumi, al que le toca asumir la condición de Comandante de las fuerzas combatientes, sea un licenciado del Ejército (30), un hombre que ha recibido una instrucción militar que ahora utilizará para enfrentarse al orden establecido y a sus antiguos compañeros de armas. Es evidente que ello crea simbólicamente una imagen de una creciente beligerancia y mejor "preparación militar" en las "nuevas generaciones" de comuneros. Pero se trata de una mayor combatividad que sus mayores, no de una oposición entre un pasado "tradicional" de suprema "pasividad", y un presente (y futuro) de combatividad y revolución. No hay contradicción ni tajante negación del pasado, hay evolución, puntos de contacto y discrepancia, semejanzas y diferencias sutiles. Pero la imagen final que se crea es la que muestra a Benito Castro y sus compañeros como una propuesta que se lanza hacia los tiempos futuros.

Es en este contexto que el significado de la "historia del Fiero Vásquez" suscita planteamientos insólitos y audaces, pues todo lo anteriormente expuesto apunta a considerar que la novela tiende a exaltar la violencia como método correcto en las luchas campe-

lidad: recordemos que el final de la novela está ambientado en 1928, cuando el período de Leguía llegaba a su fin. Todo ello remite a una evidente capacidad de la máxima creación de Ciro Alegría de aludir a la realidad sin dejar de ser obra de arte; de hablar de un "mundo" histórico de manera artísticamente persuasiva. Ver: Wilfredo Kapsoli y Wilson Reátegui: El campesino peruano: 1919-30. UNMSM, Seminario de Historia Andina, 1972 (Mimeo), 214 págs. más numerosos cuadros anexos. (Es la publicación de la tesis Situación Seconómica-social del campesinado peruano (1919-1930). Lima, UNMSM, Programa Académico de Letras, 1969. 'Dos capítulos de esta tesis, 'en' versión ligeramente distinta a la de 1972, habían sido publicados en la revista "Campesino". Lima, Año I, No. 1, mayo agosto de 1969, pp. 1-30). Posteriormente Kapsoli ha incorporado una versión sintética del período 1919-30 en su libro Movimientos campesinos en el Perú 1879-1965. Lima, Deva editores, 1977.

(30) La figura del "licenciado" es un tópico de la literatura indigenista que convendría estudiar. El "licenciado" es siempre un privilegiado agente del "cambio" en su comunidad; a su regreso del servicio militar (realizado en ciudades de la costa, con frecuencia en Lima) será uno de los partidarios del "progreso" y de la "modernización" de las costumbres. Es ciertamente sintomático que de López Albújar a Scorza (dejando de lado, para estos efectos, la indagación de si Scorza es "indigenista" o no) el "licenciado" constituye un personaje que interesa mucho al novelista. En Scorza, por ejemplo, se utiliza reiteradamente a comuneros "licenciados" para que encabecen diversas acciones de fuerza, para que pongan sus conocimientos militares al servicio de la comunidad. En las cinco novelas de la saga de Scorza se repite la misma situación: son los "licenciados" de la comunidad los que dirigen las acciones contra las "fuerzas del orden" a las que han pertenecido. C.F. "Trayectoria y sentido de la peripecia de los "comuneros emigrados" en EMAA", op. cit., p. 141. 
sinas $\mathrm{y}$, asimismo, da a entender que, en un parámetro histórico, el indio se está transformando en un ser más luchador que en el pasado (31). Por ello es que resulta tan coherente el capítulo final de la novela y tan consistente la opción por la lucha armada: la significación de este capítulo está en armonía con el sentido que emerge de la novela en su totalidad. No dejemos sin destacar que en este capítulo de violencia final Fidel Vásquez es el combatiente más joven y el primero en caer en los enfrentamientos iniciales con las "fuerzas del orden". La sombra del Fiero acompaña al lector, por tanto, hasta las postrimerías de la novela.

Una última proposición, derivada de las anteriores, nos lleva a preguntarnos si acaso la condición de "brazo armado no oficial" de la banda del Fiero respecto a la comunidad de Rumi no constituye un "modelo para armar" que se postula para las luchas campesinas. Este "modelo" significa, como es obvio, desvincular al campesino de la violencia armada directa, y así impedir, como dice Rosendo Maqui, que se "den pretextos pa que destruyan la comunidad po la juerza", y evitando la represión contra los comuneros quienes, como todo campesino, están atados a la tierra y no pueden escapar a las "fuerzas del orden". Un bandolero-guerrillero, en cambio, tiene mil escondites naturales en la serranía del Perú; un guerrillero (en igual medida que un bandolero tradicional) es necesariamente nómade y eso mismo le hace aplicar métodos de combate específicos, caquéllos de la "guerra de gue rrillas", que señalan la conveniencia de atacar por sorpresa, de tener siempre la capaciadad de huir y mantener permanentemente contactos útiles con la población rural. La novela contiene, significativamente, un ejemplo que ilustra la eficacia de las técnicas de la guerrilla: el de Eleodoro Benel, cuya guerrilla resistió cinco años la persecución del ejército regular operando en las serranías de Cajamarca. Considero de capital importancia para penetrar en el sentido último de la novela estudiar este tema: en las páginas finales de El mundo es ancho y ajeno, en la víspera misma del primer combate, Benito Castro - que, siendo soldado, había peleado contra la guerrilla de Benel- piensa, equivocadamente, que la lucha armada que va a empezar, será similar a la de Benel:

-No, Clemente, qué se te ocurre. Tienen pa rato con noso-

(31) Lo cual tendría su equivalencia en el cambio, hacia 1930, de las modalidades de la lucha campesina en el Perú, en el esquema de Quijano (C.F. nota 27); cambio que conlleva una transformación hacia formas más violentas de protesta. 
tros, y si llega a prender una buena revolución... Fíjate lo que pasó con Benel. Aguantó cinco años...

-Es que ese tenía plata...

-No creas; lo que supo es ir creciendo. Yo estaba allá y vi cómo lo ayudaba el pueblo. (p. 935)

Esta apreciación de Benito entraña una incorrecta perspectiva, que no toma en cuenta el carácter nómade que, a diferencia de un campesino, tiene que tener un guerrillero, su aptitud para despla. zarse continuamente, para atacar por sorpresa y para eludir siempre el combate generalizado de la guerra convencional. Las características de las técnicas de lucha de Benel (y esto es igualmente válido para el Fiero y su banda) quedan claramente explicitadas como aquéllas que corresponden a una guerra de guerrillas:

El guerrillero estaba en las cercanías del departamento de Cajamarca, combatiendo desde el año 22. Al principio controló varias provincias, pero después se quedó encerrado en la de Chota. Era bastante (..) Los guardias civiles -que ya habían aparecido, muy orgullosos, para reemplazar a la gendarmería- o la tropa, enviaban grupos de sorpresa. Los sorprendidos eran ellos. Cuando menos lo pensaban, recibían una granizada de balas. Ningún bando se daba cuartel y hombre preso era hombre muerto. ¿Grandes operaciones? Benel se escurría para caer por la retaguardia, ayudado por los campesinos, que eran soldados ocasionales y siempre sus espías Lis regimientos volvían a la ciudad de Cajamarca, que era la base de operaciones, diezmados. Lo que no impdía que los clasescy los soldados vendieran al doctor Murga, agente de Benel, las balas de máuser (...) a veinte centavos cada una. (pp. 900-1).

El capítulo final de El mundo es ancho y ajeno importa, en cambio -como hemos visto-, la aceptación de la violencia revolucionaria de todo un pueblo (un fragmento de pueblo) en armas. Esto implícitamente significa una opción distinta a la de la guerrilla y la figura del "brazo armado no oficial" que representa la banda del Fiero. Sin embargo la novela contiene una dialéctica compleja: el mismo Rosendo Maqui había considerado - correctamente- imposible de triunfar (aun si se expandiera un poco) a una sublevación masiva de los comuneros de Rumi (con lo cual queda precisamente acentuada la conveniencia de los métodos guerrilleros); dice Rosendo al oponerse a una resistencia general de comuneros más los bandidos del Fiero:

... bien quisiera que venga, pero será más malo tovía. Será el fin de todos, de todos, de toda la comunidá. Unos morirían, 
otros serón llevados a la córcel y otros de peones ... Si triunfamos, triunfaremos un mes, tres meses, seis meses.... pero vendrá tropa y nos arrasará... Tovía podemos hacer güena la tierra de Yanañahui. La vida es de los que trabajan su tierra. (p. 601).

Benito Castro se equivoca, pues, al pensar que "su" revolución pueda triunfar. Como una posibilidad que existiera en el fondo del escenario, la novela deja en suspenso una interrogante: acaso si Benito Castro aplicara los métodos del Fiero Vásquez, las cosas serían distintas. Assí es como, al final de la novela, se siente más que nunca la ausencia de aquel bandolero que se transforma en un guerrillero que combate por las causas de la Comunidad; se extraña al hombre que tanto había influido en Rumi y que por decisión propia -que aprobarían después los comuneros - se convirtió en el "brazo armado no oficial" de la comunidad de Rumi. Acaso si con este "modelo" de resistencia campesina la comunidad de Rumi no hubiese sido destruida...

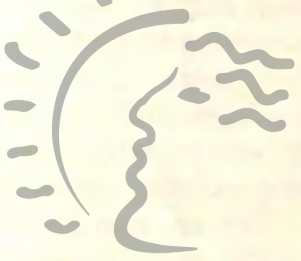

Biblioteca de Letras "Jorge Puccinelli Converso» 